\title{
Highly Porous Heteroatom Doped-Carbon Derived from Orange Peel as Electrode Materials for High-Performance Supercapacitors
}

Feifei Ding ${ }^{l}$, Jin $\mathrm{Li}^{1}$, Hongmei Du ${ }^{1,2, *}$, Jinsheng Zhao ${ }^{l}$, Konggang $Q u^{l}$, Yunwu Li ${ }^{l}$, Xianxi Zhang ${ }^{1, *}$, Yan Zhang ${ }^{l}$, Yao Qin ${ }^{l}$ and Weiyu $\mathrm{Lu}^{l}$

${ }^{1}$ School of Chemistry and Chemical Engineering, Liaocheng University, Shandong Provincial Key Laboratory of Chemical Energy Storage and Novel Cell Technology, Liaocheng 252059, China

${ }^{2}$ Key Laboratory of Advanced Energy Materials Chemistry (Ministry of Education), Nankai University, Tianjin 300071, China

*E-mail: duhongmei@1cu.edu.cn, zhangxianxi@1cu.edu.cn

doi: $10.20964 / 2020.06 .75$

Received: 2 February 2020 / Accepted: 31 March 2020 / Published: 10 May 2020

Biomass conversion to heteroatom-doped carbon materials is considered to be an effective and inexpensive method for energy conversion. Orange peel is rich in the elements carbon, nitrogen and oxygen. Herein, nitrogen and oxygen co-doped carbon is prepared by high-temperature carbonization and activation of orange peels. Two activating agents, $\mathrm{KOH}$ and $\mathrm{K}_{2} \mathrm{FeO}_{4}$, are adopted in the preparation. The OC-1-K sample derived from orange peel activated by $\mathrm{KOH}$ has a large specific surface area of $917.66 \mathrm{~cm}^{2} \mathrm{~g}^{-1}$. When used as a supecapacitor electrode material, the OC-1-K sample displays a high specific capacitance of $282.3 \mathrm{~F} \mathrm{~g}^{-1}$ at $1 \mathrm{~A} \mathrm{~g}^{-1}$. Even when the current density increases to $20 \mathrm{~A} \mathrm{~g}^{-1}$, the discharge capacity is $212 \mathrm{~F} \mathrm{~g}^{-1}$, indicating good rate performance. After 4000 chargedischarge cycles in $2 \mathrm{~mol} \mathrm{~L}^{-1} \mathrm{KOH}$ electrolyte, the capacitance is maintained at $209.8 \mathrm{~F} \mathrm{~g}^{-1}$ at $20 \mathrm{~A} \mathrm{~g} \mathrm{~g}^{-1}$, achieving good cycling stability. All these results are superior to those of the OC-1-G sample obtained by $\mathrm{K}_{2} \mathrm{FeO}_{4}$ activation. These results indicate that $\mathrm{KOH}$ is more effective in activating orange peels. The excellent electrochemical performance of the OC-1-K sample suggests good application prospects in supercapacitors.

Keywords: biomass-derived carbon, porous material, supercapacitive, symmetric supercapacitor

\section{$\underline{\text { FULL TEXT }}$}

(C) 2020 The Authors. Published by ESG (www.electrochemsci.org). This article is an open access article distributed under the terms and conditions of the Creative Commons Attribution license (http://creativecommons.org/licenses/by/4.0/). 